\title{
Changes in Hepatic Enzyme Activities in Transgenic Mice Carrying Human Prototype c-Ha-ras Gene Treated with Diethylnitrosamine
}

\author{
Toshiro ARAI ${ }^{1)}$, Takashi OGAWA ${ }^{1)}$, Masako NAKAMURA ${ }^{1)}$, Masaru HOSOYA ${ }^{1)}$ and Yasuyuki OHNISHI ${ }^{2)}$ \\ ${ }^{1)}$ Division of Veterinary Biochemistry, Nippon Veterinary and Animal Science University, 1-7-1 Kyonancho, Musashino, Tokyo $180-8602$ \\ and ${ }^{2)}$ Central Institute of Experimental Animals, 1430 Nogawa, Miyamae-ku, Kawasaki 216-0001, Japan
}

(Received 26 April 2002/Accepted 12 July 2002)

ABSTRACT. Activities of malate dehydrogenase (MDH) and aspartate aminotransferase in the malate-aspartate shuttle were significantly increased in the cytosolic fractions of livers with early neoplastic symptoms such as swelling and discoloration in transgenic mice carrying the prototype human c-Ha-ras gene, Tg-rasH2 mice, which were administered with diethylnitrosamine (DEN) as a carcinogenic chemical at a dose of $200 \mathrm{mg} / \mathrm{kg}$ body weight. Cytosolic MDH/LDH (lactate dehydrogenase) (ML) ratio increased significantly and w as considered to be a useful marker to characterize the energy metabolism at early neoplastic stage in livers of the $\mathrm{Tg}$-ras $\mathrm{H} 2 \mathrm{mice}$. KEY WORDS: aspartate aminotransferase, malate dehydrogenase, transgenic mouse.

J. Vet. Med. Sci. 64(11): 1065-1067, 2002

A transgenic mouse strain carrying human prototype cHa ras gene, Tg-rasH2 mice, was established by Saitoh et al. [20]. These mice show high and rapid susceptibility to various carcinogens and are considered to be promising as an animal model for an alternative rapid carcinogenicity test [25]. Spontaneous hepatocellular carcinomas, forestomach papillomas, skin papillomas and lymphomas were observed in 20 to $30 \%$ of Tg-rasH 2 mice by 82 weeks and these incidences were increased by treatments of some kinds of carcinogens including N,N'-diethylnitrosamine (DEN) known as Salmonella mutagenesis assay-positive trans-species carcinogen [24]. The major target organs of DEN are the liver, lung, forestomach and hematopoietic system [12]. In our previous reports, Tg-rasH2 mice were characterized by stable activities of some enzymes related to drug detoxication and energy metabolism in their livers and kidneys compared to those in the non-transgenic control [18]. On the other hand, it has been reported that activities of enzymes in the glycolysis and the pentose phosphate pathway are significantly increased in developed tumor cells [1, 7, 17]. Activities and mRNA expression of malate dehydrogenase $(\mathrm{MDH})$ in the malate-aspartate shuttle are significantly induced in the early stage of testicular tumor of dogs [3]. In the present study, activities of several enzymes related to energy metabolism were measured in livers of the $\mathrm{Tg}$-rasH2 mice treated with DEN to investigate availability of certain enzymes as a diagnostic marker for energy metabolism at the early stage in tumor cells.

F1 hybrids of a transgenic male $\mathrm{C} 57 \mathrm{BL} / 6 \mathrm{~J}$, Tg-rasH2, mice and normal female BALB/cByJ mice were used. The F1 offsprings were screened by polymerase chain reaction (PCR), and divided into transgenic (-/Tg) and non-transgenic mice (-/-). Six-week-old male transgenic mice, which showed high expression of ras gene, were used in the present study. Their mean ( \pm SD) body weights were 16.8 $( \pm 0.4) \mathrm{g}$. Mice were housed in an air-conditioned room (23 $\pm 2{ }^{\circ} \mathrm{C}, 55 \pm 10 \%$ ) with a light period of $12 \mathrm{hr}$. Food and water were available ad libitum. All procedures involving laboratory animals were performed in accordance with the care and use guidelines of the Central Institute of Experimental Animals (Kawasaki, Japan). Male Tg-rasH2 mice divided into two groups containing of 10 mice each. One group (DEN-treated) was given intraperitoneally N,N'diethylnitrosamine (DEN) ( SIGMA, St. Louis, MO, U.S.A.) dissolved in phosphate buffered saline (PBS) at a dose of $200 \mathrm{mg} / \mathrm{kg}$ body weight. The second group (control) was given PBS at $0.1 \mathrm{~m} l / 10 \mathrm{~g}$ body weight intraperitoneally as vehicle treated control. Animals were weighed and sacrificed by cervical section under ether euthanasia, 4 weeks after the DEN administration. Blood was withdrawn into heparinized tube from the jugular vein of the animal. Plasma was obtained by centrifugation at $4^{\circ} \mathrm{C}$. Plasma glucose concentrations were measured by the glucose-oxidase method [11] and plasma free fatty acids (FFA) concentrations were measured by a commercial kit, NEFA-C test Wako (Wako Pure Chemical Industries, Tokyo, Japan). The livers were removed immediately from the sacrificed animals and homogenized with 4 volumes of STE solution ( $0.25 \mathrm{~mol} / l$ sucrose, $10 \mathrm{mmol} / l$ Tris- $\mathrm{HCl}, \mathrm{pH} 7.5,2 \mathrm{mmol} / l$ ethyleneglycol tetraacetic acid) in a Potter glass homogenizer. Cytosolic and mitochondrial fractions were isolated from the above homogenates by the method described previously [2].

The enzyme activities were measured by the previous reported methods: lactate dehydrogenase (LDH) [14], glutamate dehydrogenase (GLDH) [21], hexokinase (HK) and glucokinase (GLK) [23], glucose-6-phosphate dehydrogenase (G6PD) [4], glycerol kinase (GK) [15], malate dehydrogenase $(\mathrm{MDH})$ [5], aspartate aminotransferase (AST) [19], and alanine aminotransferase (ALT)[10]. LDH was used as the marker enzyme in the cytosolic fractions, and GLDH as the marker enzyme in the mitochondrial fractions. $\mathrm{MDH}$ and AST were the pivotal enzymes in the malateaspartate shuttle. HK and GLK were the rate-limiting 
enzymes in the glycolysis and G6PD was the rate-limiting enzyme in the pentose phosphate pathway. GK and ALT were used as crucial enzyme in the glycerol utilization and transamination, respectively. All enzymatic analyses were conducted at 24 to $26^{\circ} \mathrm{C}$. The enzyme activities were expressed as nmol of substrate degraded per min per mg of protein. Protein concentrations were measured by the method of Bradford [6] with bovine serum albumin as the standard. Cytosolic MDH/LDH activity ratio (ML ratio) was also calculated as MDH specific activity divided by LDH specific activity.

Total RNA was extracted from mouse liver using a commercial RNA isolation kit, RNeasy Mini Kit (QIAGEN, Hilden, Germany). Reverse transcriptase polymerase chain reaction (RT-PCR) was used to detect the conserved region of the cytosolic MDH mRNA, positioned at 283-715 base pairs of the cDNA sequence of mouse liver MDH (GenBank accession no. NM008618) [13]. Glyceraldehyde-3-phosphate dehydrogenase (GAPDH) mRNA was used as a control for the PCR technique. The RT-PCR of MDH and GAPDH was carried out using the previously reported method [24] and the PCR product after 35 cycles using a DNA thermal cycler (Perkin Elmer, Norwalk, CT, U.S.A.) was electrophoresed in $2 \%$ agarose gels and visualized by ethidium bromide staining.

All values are expressed as the mean \pm SD and the difference between means were analyzed by Student's $t$-test.

Swelling and discoloration were decided as the early neoplastic symptoms in livers of Tg-rasH2 mice at necropsy. Five mice of the DEN treated group and 2 mice of the control group showed these symptoms in their livers. DEN treated mice were further divided into 2 groups, DEN-I $(n=5)$ with swelling and discoloration and DEN-II $(n=5)$ without these symptoms. Eight mice, which did not show the above swelling and discoloration after PBS administration, were used as the controls. There were no significant differences in body weights, plasma glucose and FFA concentrations between these three groups, respectively (Table 1). Hepatic enzyme activities in mice are shown in Table 2. There were no significant differences for cytosolic HK,
Table 1. Comparison of final body weights, plasma glucose and FFA concentrations in Tg-rasH2 mice treated with DEN

\begin{tabular}{lrcc}
\hline & DEN-I $(\mathrm{n}=5)$ & DEN-II $(\mathrm{n}=5)$ & Control $(\mathrm{n}=8)$ \\
\hline Body weight $(\mathrm{g})$ & $24.7 \pm 1.0$ & $25.4 \pm 1.2$ & $26.2 \pm 1.1$ \\
Plasma glucose $(\mathrm{mmol} / l) 8.7 \pm 0.7$ & $9.4 \pm 0.7$ & $9.6 \pm 0.8$ \\
Plasma FFA $(\mathrm{mEq} / \mathrm{l})$ & $2.8 \pm 0.4$ & $2.7 \pm 0.2$ & $2.7 \pm 0.2$ \\
\hline
\end{tabular}

Values are presented as mean \pm SD.

GLK, G6PD, GK, ALT, LDH and mitochondrial GLDH, AST, MDH activities between the groups. Activities of AST and MDH and ML ratio in the cytosolic fractions increased significantly in the DEN-I group compared to those in the others. In the livers of two mice with the above early neoplastic symptoms after PBS administration, the mean MDH and AST activities were 4,125 and 1,004 nmol/ min per $\mathrm{mg}$ of protein, respectively. The mean ML ratio in these two mice was 3.50. These values were considerably higher than the control values. When the amplification of the cytoslic MDH cDNA (with a predicted size of 433 base pairs) by RT-PCR was analyzed, the cytosolic MDH fragment was detected as clear band with almost same staining strength to the fragment of glyceraldehyde-3-phosphate dehydrogenase (GAPDH) (450 base pairs) used as internal standard in the PCR products of livers of mice with 4,284 and 4,090 $\mathrm{nmol} / \mathrm{min}$ per $\mathrm{mg}$ protein of $\mathrm{MDH}$ activities in the DEN-I group, respectively (Fig. 1, lane 2 and 3). Whereas, the staining strength of MDH fragment of the liver from a control mouse with 2,634 nmol/min per mg protein as $\mathrm{MDH}$ activities was weaker than those in the DEN-I group (Fig. 1, lane 1).

Single administration of DEN induced neoplastic changes in livers of $50 \%$ of Tg-rasH2 mice until 4 weeks after the administration. However, the neoplastic change was not so severe considering the symptoms such as swelling and discoloration, and was considered to be the early stage of tumor. In such early neoplastic stage, only cytosolic activities of MDH and AST in the malate-aspartate shuttle were increased remarkably. Since MDH is a rate limiting

Table 2. Enzyme activities in livers of Tg-rasH2 mice treated with DEN

\begin{tabular}{llccc}
\hline & & DEN-I $(\mathrm{n}=5)$ & DEN-II(n=5) & Control $(\mathrm{n}=8)$ \\
\hline Cytosol & HK & $3.0 \pm 0.9$ & $2.8 \pm 1.2$ & $2.5 \pm 1.0$ \\
& GLK & $1.8 \pm 0.8$ & $1.5 \pm 0.4$ & $1.6 \pm 0.4$ \\
& G6PD & $3.9 \pm 2.1$ & $3.2 \pm 0.8$ & $2.7 \pm 0.6$ \\
& GK & $1.4 \pm 0.4$ & $1.4 \pm 0.2$ & $1.5 \pm 0.4$ \\
& AST & $917 \pm 151^{*}$ & $652 \pm 146$ & $645 \pm 101$ \\
& ALT & $138 \pm 43$ & $116 \pm 18$ & $110 \pm 13$ \\
& MDH & $3,892 \pm 420^{*}$ & $2,955 \pm 340$ & $2,758 \pm 250$ \\
& LDH & $1,035 \pm 207$ & $1,141 \pm 141$ & $985 \pm 138$ \\
& ML ratio & $3.8 \pm 0.2 * *$ & $2.6 \pm 0.4$ & $2.8 \pm 0.3$ \\
& GLDH & $1,257 \pm 473$ & $1,103 \pm 113$ & $1,110 \pm 320$ \\
& AST & $1,050 \pm 103$ & $980 \pm 184$ & $939 \pm 240$ \\
& MDH & $3,305 \pm 320$ & $3,421 \pm 319$ & $3,443 \pm 400$ \\
\hline
\end{tabular}

Enzyme activities (mean $\pm \mathrm{SD}$ ) are presented as $\mathrm{nmol} / \mathrm{min}$ per $\mathrm{mg}$ of protein.

*Significantly higher $(\mathrm{p}<0.05)$ than the control values.

**Significantly higher $(\mathrm{p}<0.01)$ than the control values. 


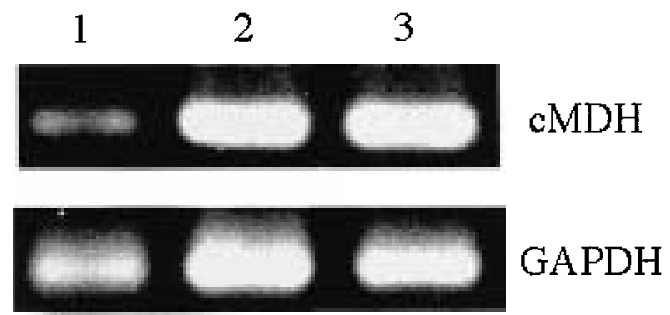

Fig. 1. Analysis of cytosolic malate dehydrogenase mRNA with RT-PCR in livers of Tg-rasH2 mice treated with DEN. Glyceraldehyde-3-phosphate dehydrogenase (GAPDH) mRNA was determined as a control for the PCR technique. mRNA of MDH and GAPDH were amplified in different tubes each other. PCR products were stained with ethidium bromide. Lane 1, control mouse; lane 2 and 3; DEN -I group mice.

enzyme for the malate-aspartate shuttle [16], the increased activities of MDH will result in the production of more ATP in the mitochondria. Increasing in MDH activities is induced by some kinds of factors such as excess of glucose utilization [8] and intensive training [2] in animal tissues. Although activities of enzymes in glycolysis and pentose phosphate pathway were significantly increased in well developed tumor cells $[1,7]$, these enzymes activities were not so high at the early neoplastic stage [3]. MDH and AST may be one of important factors to lead the cytosolic energy metabolism to more ATP production before activation of glycolysis and pentose phosphate pathway at the early stage of tumor. It has been reported that cells transfected with activated ras oncogene showed the increased rate of glucose uptake and utilization [9]. The activated c-Ha-ras transformed NIH/3T3 cell line shows significantly higher activities of enzymes related to energy metabolism than untransformed cell line [22]. As cells with ras overexpression show various changes in energy metabolism as mentioned above, effect of overexpression of ras oncogene on activation of the malate-aspartate shuttle should be further studied in livers of Tg-rasH2 mice. Moreover, metabolic change for longer duration over 4 weeks and relationship between cytosolic and mitochondrial enzymes activities changes should be further studied in Tg-rasH2 mice administrated with DEN. On the other hand, the ML ratio is considered to be a good indicator to evaluate energy metabolism in animal tissues, and the increased ML ratio appears to reflect elevated metabolic conditions which need more ATP production. The ML ratio is also considered to be a useful diagnostic marker to evaluate energy metabolism in early neoplastic stage in livers of Tg-rasH2 mice.

\section{REFERENCES}

1. Arai, T., Ogino, T., Gunji, M., Washizu, T., Komori, S. and Washizu, M. 1997. Res. Vet. Sci. 62: 85-86.

2. Arai, T., Takahashi, M., Araki, K. and Washizu, T. 2001. Vet. Res. Commun. 25: 577-583.
3. Arai, T., Ogawa, T., Hosoya, M., Nakamura, M. and Kawakami, E. 2002. Vet. Res Commun. 26: (in press).

4. Bergmeyer, H. U., Gawehn, K. and Grassl, M. 1974. pp. 458 459. In: Methods of Enzymatic Analysis, vol. 1 (Bergmeyer, H. U. ed.), Academic Press, New York.

5. Bergmeyer, H. U. and Bernt, E. 1974. pp. 613-617. In: Methods of Enzymatic Analysis, vol. 2 (Bergmeyer, H. U. ed.), Academic Press, New York.

6. Bradford, M. M. 1976. Anal. Biochem. 72: 248-254.

7. Brocklehurst, D., Champion, A. E., Cheek, T. R. J. and Dewhurst, D. G. 1986. Tumour 7: 99-104.

8. Eto, K., Tsubamoto, Y., Terauchi, Y., Sugiyama, T., Kishimoto, T., Takahashi, N., Yamauchi, N., Kubota, N., Maruyama, S., Aizawa, T., Akanuma, Y., Aizawa, S., Kasai, H., Yazaki, Y. and Kadowaki, T. 1999. Science 283: 981-985.

9. Flier J. S., Mueckler, M. M., Usher, P. and Lodish, H. P. 1987. Science 235: 1492-1495.

10. Horder, M. and Rej, R. 1983. pp. 444-456. In: Methods of Enzymatic Analysis, vol.3, 3rd ed. (Bergmeyer, H. U. ed.), $\mathrm{VCH}$, New York.

11. Huggett, A. G. and Nixon, D. A. 1957. Lancet 2: 368-370.

12. International Agency for Research on Cancer. 1978. pp. 83124. In: IARC Monographs on the Evaluation of the Carcinogenic RISK of Chemicals to Humans, vol.17, I ARC, Lyon.

13. Joh, T., Takashima, H., Tsuzuki, T., Setoyama, C., Shimada, K., Tanase, S., Kuramitsu, S., Kagamiyama, H. and Morino, Y. 1987. J. Biol. Chem. 262: 15127-15131.

14. Kaloustian, H. D., Stolzenbach, F. E., Everse, J. and Kaplan, N. O. 1969. J. Biol. Chem. 244: 2891-2901.

15. Kennedy, E. P. 1962. pp. 476-482. In: Methods in Enzymology, vol.5 (Colowick, S. P. and Kaplan, N. O. eds.), Academic Press, New York.

16. MacDonald, M. J. 1982. Arch. Biochem. Biophys. 213: 643649.

17. Nerurkar, V. R., Ishwad, C. S., Seshadri, R., Naik, S. N. and Lalitha, V. S. 1990. J. Comp. Pathol. 102: 191-195.

18. Ohnishi, Y., Arai, T., Koshirakawa, M., Horii, N., Nakajo, S., Urano, K., Usui, T., Tamaoki, N. and Ueyama, Y. 2001. Exp. Anim. (Tokyo) 50: 33-39.

19. Rej, R. and Horder, M. 1983. pp. 416-433. In: Methods of Enzymatic Analysis, vol.3, 3rd ed. (Bergmeyer, H. U. ed.), $\mathrm{VCH}$, New York.

20. Saitoh, A., Kimura, M., Takahashi, R., Yokoyama, M., Nomura, T., Ozawa, M., Sekiya, T., Nishimura, S. and Katsuki, M. 1990. Oncogene 5: 1195-1200.

21. Schmidt, E. 1974. pp. 650-655. In: Methods of Enzymatic Analysis, vol. 2 (Bergmeyer, H. U. ed.), Academic Press, New York.

22. Shinohara, N., Ogiso, Y., Arai, T., Takami, S., Nonomura, K., Koyanagi, T. and Kuzumaki, N. 1994. Int. J. Cancer 58: 672677.

23. Vinuela, E., Salas, M. and Sols, A. 1963. J. Biol. Chem. 238: PC1175-PC1177.

24. Washizu, T., Takahashi, M., Azakami, D., Ikeda, M. and Arai, T. 2001. Vet. Res.Commun. 25: 623-629.

25. Yamamoto, S., Mitsumori, K., Kodama, Y., Matsumura, N., Manabe, S., Okamiya, H., Suzuki, H., Fukuda, T., Sakamaki, Y., Sunaga, M., Nomura, G., Hioki, K., Wakana, S., Nomura, T. and Hayashi, Y. 1996. Carcinogenesis 17: 2455-2461.

26. Yamamoto, S., Urano, K., Koizumi, H., Wakana, S., Hioki, K., Mitsumori, K., Kurokawa, Y., Hayashi, Y. and Nomura, T. 1998. Environ. Health Perspec. 106: 57-69. 